\title{
Ulotomia: coadjuvante do tratamento da má oclusão
}

\author{
Ulotomia: adjunctive treatment of malocclusion
}

\author{
Rachel Reinaldo Arnaud" \\ Manuela Gouvêa Campêlo dos Santos** \\ Ana Maria Gondim Valença** \\ Franklin Delano Soares Forte ${ }^{* * * *}$ \\ Karina Jerônimo Rodrigues Santiago Lima ${ }^{* * * *}$ \\ Rejane Targino Soares Beltrão
}

\section{Resumo}

Objetivo: o objetivo deste trabalho é relatar um caso clínico, no qual a técnica cirúrgica de ulotomia foi utilizada como tratamento inicial de correção de má oclusão dental, evitando maiores alterações na oclusão. Relato de caso: Uma paciente de sete anos de idade, sexo feminino, procurou atendimento odontológico referindo apresentar um atraso na erupção do elemento dentário 12. Foi observada a presença de tecido gengival de coloração mais pálida e que, ao toque, evidenciava-se a borda incisal do referido elemento dentário. Além disso, foi verificada a presença de inflamação e hiperplasia gengival na região dos dentes ântero-superiores, devido aos problemas oclusais, que impediam o fechamento normal da boca, levando à paciente à condição de respiradora bucal. Dessa forma, optou-se pela ulotomia por se tratar de um procedimento cirúrgico minimamente invasivo, visando apenas a exérese do tecido gengival que revestia a coroa de dente não irrompido, permitindo assim um caminho desimpedido para vir a ocupar a sua posição no arco dentário. Considerações finais: a ulotomia é um procedimento de fácil execução para o profissional e rápida recuperação para o paciente infantil, sendo um passo inicial para o tratamento da má-olcusão.

Palavras-chave: Erupção dentária. Ortodontia corretiva. Má oclusão.

\section{Introdução}

A erupção dentária é o processo fisiológico que, durante a formação do dente migra, da posição intra-óssea até uma posição funcional na cavidade oral ${ }^{1}$.

Vários fatores, sistêmicos e locais, podem, com o tempo, interferir na sequência de erupção dos dentes permanentes, dentre os fatores sistêmicos são apontados o hipopituitarismo, o hipotireoidismo e a disostose cleidocraneana; e como fatores locais destacam-se a retenção prolongada do elemento dentário, a perda precoce ou o trauma nos dentes decíduos, o odontoma, os dentes supranumerários, $\operatorname{cistos}^{2}$ e a fibrose da mucosa gengival ${ }^{3,4}$.

Em casos de fibrose da mucosa gengival, o dente permanente pode perder a força eruptiva, devido a essa barreira de tecido, na superfície oclusal ou incisal. Dessa forma, o germe do dente permanente não é capaz de penetrar o tecido gengival ${ }^{5}$.

Na clínica odontopediátrica, são comuns situações nas quais há a impacção de elementos dentários, fato que pode acarretar transtornos para a dentição em desenvolvimento. Particularmente, o atraso no processo de erupção dentária gerando inclinações e/ou giroversões dos dentes adjacentes ao espaço e extrusão do dente antagonista. Para evitar tais

Mestre em Odontologia, professora assistente do Centro Universitário de João Pessoa (Unipê). João Pessoa, Paraíba, Brasil.

Mestre em Odontologia, professora de Odontologia da Universidade Estadual da Paraíba (UEPB). Campina Grande, Paraíba, Brasil.

Doutora em Odontologia, professora associada do Departamento de Clínica e Odontologia Social da Universidade Federal da Paraíba (UFPB). João Pessoa, Paraíba, Brasil.

**** Doutor em Odontologia, professor adjunto do Departamento de Clínica e Odontologia Social da Universidade Federal da Paraíba (UFPB). João Pessoa, Paraíba, Brasil.

***** Doutora em Odontologia, professora adjunta do Departamento de Clínica e Odontologia Social da Universidade Federal da Paraíba (UFPB). João Pessoa, Paraíba, Brasil.

Doutor em Odontologia, professora adjunta de Ortodontia da Universidade Federal da Paraíba (UFPB). João Pessoa, Paraíba, Brasil. 
transtornos, deve-se indicar a ulotomia, procedimento cirúrgico, que consiste na exérese do tecido gengival que reveste a face incisal ou oclusal da coroa dentária de um dente decíduo ou permanente não irrompido, de forma a lhe permitir um caminho livre para ocupar a sua posição normal no arco dentário ${ }^{6,7}$.

Além da fibrose gengival, a ulotomia está indicada para os casos em que, sem outro motivo aparente, o dente tem sua erupção retardada, como também, para dentes permanentes parcialmente irrompidos com erupção lenta ${ }^{8}$. Esse procedimento é indicado, também, nos casos de cistos de erupção, que podem ser chamados de hematomas de erupção, quando o quadro clínico torna-se doloroso e incômodo, com a finalidade de drenar o fluido cístico e expor a coroa do dente ao meio bucal ${ }^{6,9}$.

Exames clínicos e radiográficos detalhados da região são necessários para indicação correta dessa técnica cirúrgica. $\mathrm{O}$ exame clínico mostra a presença de uma área com aumento de volume e coloração mais pálida, pelo aumento da camada de queratina do epitélio, além de marcas contornadas, denotando a presença iminente do dente não irrompido. Radiograficamente, pode-se observar a rizogênese do dente permanente, atingindo $2 / 3$ do seu estágio (estágio 8 Nolla), e eliminar a presença de alguns fatores que podem estar associados ao retardo ou até mesmo ao impedimento da irrupção do dente e que contra-indicariam a ulotomia, como camada óssea, recobrindo a coroa dentária, má-formação dentária, presença de supranumerários, cistos ou odontomas na região, falta de espaço, agenesia e grau de formação radicular da unidade ${ }^{10}$.

A retenção de um elemento dentário pode ocasionar transtornos na dentadura mista e na dentição permanente, induzindo a uma má oclusão, devido a movimentos indesejáveis dos dentes adjacentes e antagônicos ao espaço do dente não irrompido. Dessa forma, após o processo eruptivo retardado, o dente pode irromper ectopicamente por falta de espaço o que ocasiona uma alteração no arco dentário levando a uma má oclusão. O desvio da normalidade das unidades dentárias pode variar em um leve grau de rotação ou deslocamento de um dente, até uma complexa má posição de alguns ou todos os dentes ${ }^{11}$.

Este trabalho tem por finalidade relatar um caso clínico, no qual a técnica cirúrgica de ulotomia foi utilizada como tratamento inicial de correção de má oclusão dental, evitando maiores alterações na oclusão.

\section{Relato de caso}

Paciente do sexo feminino, leucoderma, brasileira e com sete anos de idade, compareceu à Clínica da odontopediatria da Universidade Federal da Paraíba, apresentando um perfil facial acentuadamente convexo, altura facial aumentada, padrão facial com tendência vertical, prognatismo maxilar e retrognatismo mandibular e ausência (Tab. 1) de selamento labial passivo, deglutição atípica, musculatura mentoniana hipotônica, lábios ressecados e olheiras (Figuras 1A e B). Além disso, foi verificada a presença de inflamação e hiperplasia gengival na região dos dentes ântero-superiores, devido aos problemas oclusais, que impediam o fechamento normal da boca, levando a paciente à condição de respiradora bucal (Figura $2 \mathrm{~A}$ e B).

Tabela 1 - Valores da cefalometria da paciente do caso em questão

\begin{tabular}{|c|c|c|}
\hline Fatores & Valor obtido & Norma/Classif \\
\hline N-A. Pog & $18,86 \mathrm{gr}$ & $0,00+-2,00$ \\
\hline S-N.A & $86,73 \mathrm{gr}$ & 82,00 \\
\hline S-N.B & $76,76 \mathrm{gr}$ & 80,00 \\
\hline A-N.B & $9,97 \mathrm{gr}$ & 2,00 \\
\hline S-N.D & $74,12 \mathrm{gr}$ & 76,00 \\
\hline S-N.Gn & $68,32 \mathrm{gr}$ & 67,00 \\
\hline S-N.Ocl & $8,77 \mathrm{gr}$ & 14,00 \\
\hline$(\mathrm{S}-\mathrm{N}) \cdot(\mathrm{Go}-\mathrm{Me})$ & $34,00 \mathrm{gr}$ & 32,00 \\
\hline (Go-Gn).Ocl & $23,76 \mathrm{gr}$ & 18,00 \\
\hline $1 / . / 1$ & $112,42 \mathrm{gr}$ & 131,00 \\
\hline $1 / . \mathrm{NA}$ & $29,38 \mathrm{gr}$ & 22,00 \\
\hline $1 /-N A$ & $6,65 \mathrm{gr}$ & 4,00 \\
\hline /1.NB & $28,23 \mathrm{gr}$ & 25,00 \\
\hline$/ 1-N B$ & $6,92 \mathrm{~mm}$ & 4,00 \\
\hline /1.NPog & $6,06 \mathrm{~mm}$ & 0,00 \\
\hline H. ( N-B) & $19,10 \mathrm{gr}$ & $10,50+/-1,50$ \\
\hline H- Nariz & $-4,63 \mathrm{~mm}$ & $10,00+/-1,00$ \\
\hline Pog-NB & $1,30 \mathrm{~mm}$ & 0,00 \\
\hline FMIA & $52,19 \mathrm{gr}$ & 68,00 \\
\hline FMA & $28,86 \mathrm{gr}$ & 25,00 \\
\hline IMPA & $98,95 \mathrm{gr}$ & 87,00 \\
\hline
\end{tabular}

* N-A. Pog : Perfil convexo; S-N.A: Protusão maxilar; S-N.B: Retrusão mandibular; A-N.B: Cl II esquelética; 1/.NA: Inclinação superior; /1.NB: Bom posicionamento.

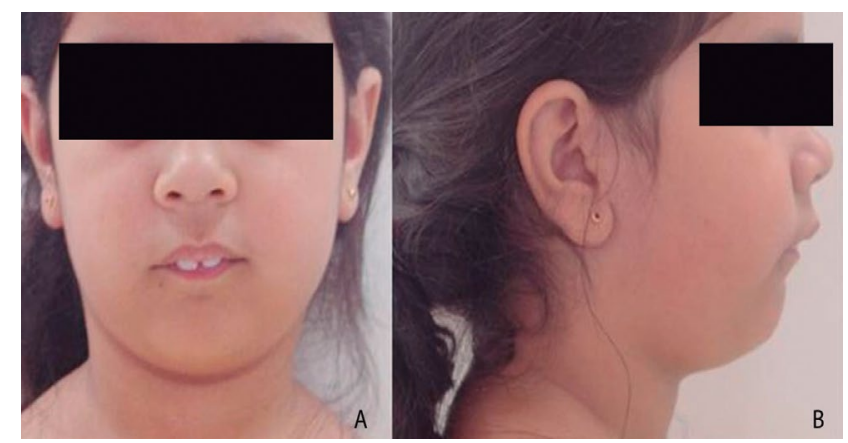

Figura 1 - A) Fotografia exta bucal frontal. B) Fotografia extabucal de perfil inicial 


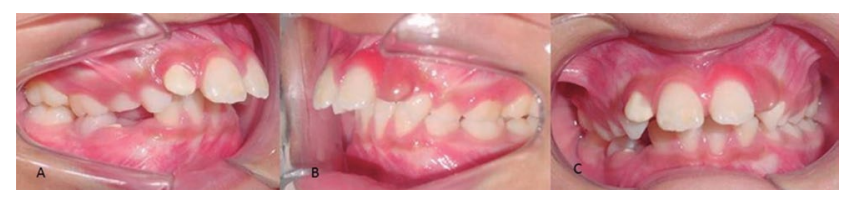

Figura 2 - A) Fotografia intrabucal lateral direita. B) Fotografia intrabucal lateral esquerda. C) Fotografia intrabucal frontal

No exame intrabucal, constatou-se que o incisivo lateral superior esquerdo não estava irrompido e não foi relatada nenhuma anormalidade que pudesse ocasionar esse retardo na erupção dentária. Clinicamente, o incisivo lateral superior esquerdo apresentava-se recoberto por um tecido gengival de coloração mais pálida e que, ao toque, evidenciava-se a borda incisal do referido elemento dentário (Figura 2C). Observa-se ainda opacidade nos incisivos centrais.

No exame oclusal, a paciente mostrou na dentadura mista, com má oclusão de Classe II, divisão um, com curva de Spee acentuada, linha média superior com desvio para esquerda em relação ao plano sagital mediano, linha média inferior coincidente com plano sagital mediano, trespasse vertical de $5 \mathrm{~mm}$, trespasse horizontal de $12 \mathrm{~mm}$. O diagnóstico cefalométrico mostrou perfil ósseo convexo, protusão maxilar, retrusão mandibular e classe II esquelética (Figura 3A e 3B).

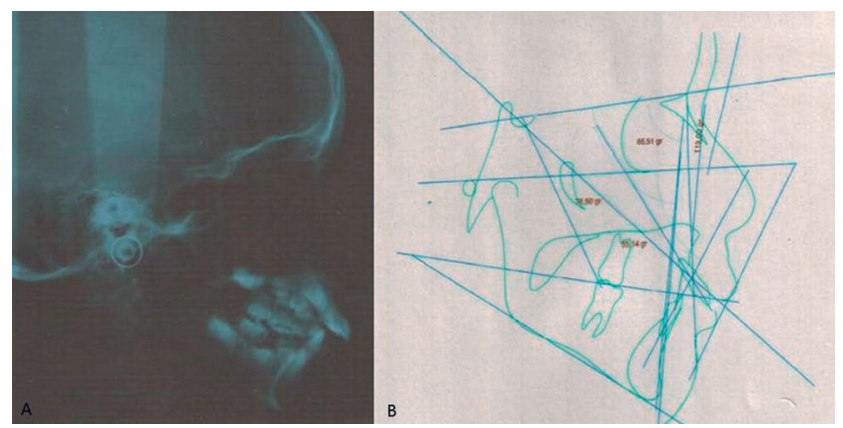

Figura 3 - A) telerradiografia em norma lateral. B) Traçado cefalométrico

O planejamento do tratamento consistiu em: cirurgia oral menor e tratamento ortopédico ( $1^{\underline{a}}$ fase), para realização da ulotomia e posterior tratamento ortodôntico ( $2^{\mathrm{a}}$ fase) para correção da má oclusão.

Com o objetivo de facilitar a erupção do incisivo lateral superior esquerdo, optou-se, inicialmente, pela realização da ulotomia, Depois de obter a autorização do responsável pelo paciente, o procedimento foi iniciado com anti-sepsia da cavidade bucal seguida de anestesia tópica e infiltrativa gengival (Figura 4A), apenas sobre a mucosa correspondente à região incisal do dente envolvido. Em seguida, realizou-se a incisão em elipse do capuz gengival que cobria o elemento, por meio de bisturi lâmina nำ15 (Figura 4B), expondo totalmente a borda incisal no sentido mésio-distal (Figura 4C e 4D). Não foi utilizado sutura, apenas a irrigação com soro fisiológico e a hemostasia por tamponamento, com gaze estéril, a fim de que a região esteja desimpedida para que o elemento permanente erupcione. Decorridos sete dias, procedeu-se à avaliação do caso, constatando-se a sua evolução satisfatória (Figura 5A), com ausência de sensibilidade pós-operatória relatada pela paciente. Na figura $5 \mathrm{~B}$, pode-se observar que o elemento 22 encontra-se em posição na cavidade bucal.

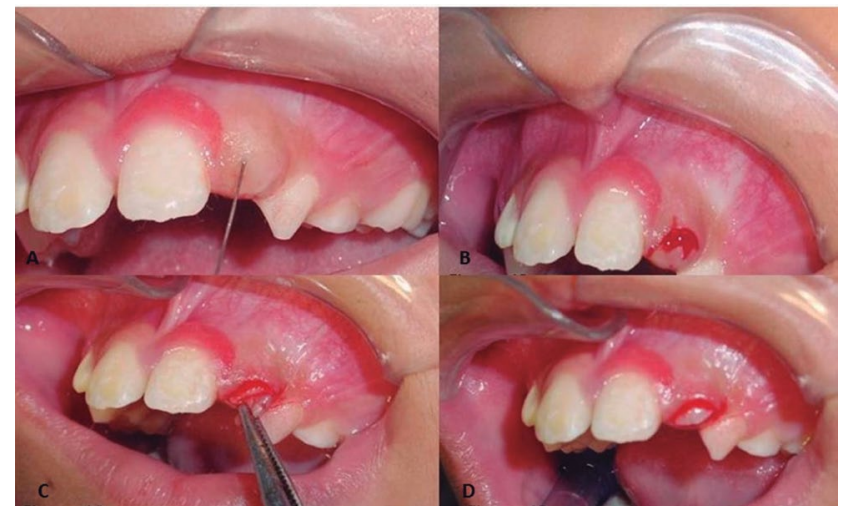

Figura 4 - A) Anestesia infiltrativa local. B) Incisão elíptica do elemento dentário com exposição da borda incisal. C) Exérese do tecido gengival. D) Exposição da borda incisal

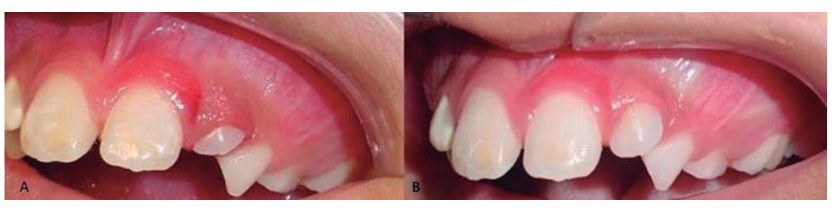

Figura 5 - A) Após 7 dias. B) Após 30 dias

Após atingidos os propósitos da fase anterior, na segunda fase objetivou-se corrigir a má oclusão de classe II divisão 1. Para isso, instalou-se o arco extrabucal conjugado para proporcionar melhor redirecionamento de crescimento mandibular, permitindo a relação entre caninos superior e inferior e entre molares superior e inferior, impedindo a relação de canino e molar. Além disso, espera-se diminuir a sobressaliência e a protrusão dos incisivos, reduzindo a interposição da língua e do lábio inferior sob os incisivos superiores, o que levará à diminuição da convexidade do perfil da paciente. Concomitantemente ao Arco Extrabucal Conjugado, instalou-se a placa lábio-ativa (Figura 6A e 6B) para correção do apinhamento ântero-inferior. Ambos os aparelhos encontram-se em utilização pela paciente, que apresenta uma excelente colaboração.

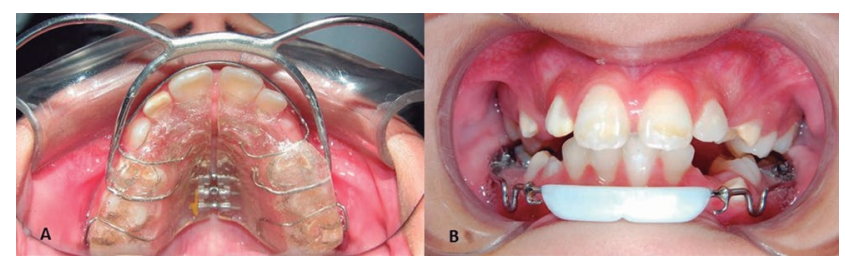

Figura 6 - A) Arco extrabucal conjugado. B) Placa lábio ativa. 


\section{Discussão}

Nas situações de retardo na erupção dentária, o cirurgião-dentista poderá fazer uso da técnica de ulotomia como opção terapêutica devido à simplicidade do procedimento e ao pós-operatório favorável. Assim, quando existe a ausência ou o atraso na erupção de um elemento dentário, deve-se procurar a causa, a fim de planejar corretamente a época e $o$ tipo de tratamento a ser adotado.

Conforme evidenciado neste caso, enquanto o dente 22 se apresentava intra-ósseo, o elemento dentário contralateral homólogo estava presente no arco, fato que trazia inquietude à paciente e aos seus familiares, que indagaram aos profissionais que acompanhavam a paciente na clínica se o dente em questão poderia não nascer ou até mesmo se ele havia se formado.

Nesse sentido, o diagnóstico diferencial é importante, pela existência de sinais semelhantes entre a agenesia dentária e o retardo na erupção, por exemplo. Dessa forma, o exame clínico associado a radiografias periapicais, oclusais e panorâmicas pode auxiliar na descoberta de possíveis agentes etiológicos que conduzam para a ausência de erupção de um dente, como odontomas e dentes supranumerários. $\mathrm{O}$ exame radiográfico permite a identificação de fatores que possam mascarar o diagnóstico e, até mesmo, contra-indicar o procedimento, como uma camada óssea, recobrindo a coroa dentária, agenesia e grau de formação radicular ${ }^{12}$. No presente caso clínico, não foi diagnosticada a presença dessa barreira óssea, nem mesmo dilaceração radicular ou tumores na área envolvida.

De acordo com alguns autore ${ }^{13}$, a presença de uma área com aumento de volume e coloração mais pálida, pela camada de queratina do epitélio mais espessa, além de marcas contornadas, denotando a presença iminente do dente não irrompido, o que foi também encontrado no presente caso.

Koch et al. ${ }^{14}$ (1995) reportaram que se a via de erupção de um dente estiver bloqueada, o obstáculo deverá ser removido, no mínimo quando a raiz desse apresentar-se formada em $2 / 3$ da sua extensão, pois, a partir do $7^{\circ}$ estágio de Nolla (1/3 de raiz formada), o dente já apresenta força eruptiva, corroborando a abordagem do caso clínico acima apresentado, que já estava com $2 / 3$ de raiz formada, correspondendo ao $8^{\circ}$ estágio de Nolla.

Uma vez indicada a ulotomia, essa deve ser feita imediatamente, pois o adiamento do ato cirúrgico pode levar a más oclusões futuras devido ao risco de movimentações dentárias com fechamento do espaço, pela inclinação dos dentes adjacentes ou extrusão do antagonista ao espaço do dente não irrompido, o que implicaria em tratamento ortodôntico posterior para recuperação do espaço perdido ${ }^{5,8,12,14-16}$. Assim, a realização imediata da ulotomia no caso estudado foi imprescindível, para preservar o espaço dentário.

De acordo com Poricelli e Ponzoni ${ }^{17}$, a técnica cirúrgica da ulotomia envolve incisões elípticas, circulares ou ovais que limitam as áreas para exérese tecidual. Sua extensão deve permitir a exposição do bordo incisal ou da face oclusal do dente. A incisão pode ser realizada com bisturi e lâmina, laser ou eletrocautério. Concordando com a técnica utilizada, segundo os autores apresentados, nesse caso, optou-se pela utilização, de bisturi e lâmina na incisão elíptica realizada.

Para Guedes-Pinto ${ }^{10}$ (1998), ao expor a coroa dentária subjacente, que pode ainda estar recoberta por tecido ósseo alveolar, deve-se efetuar cuidadosamente a osteotomia. No presente relato, após a incisão gengival, não foi verificada nenhuma presença de tecido ósseo, não necessitando osteotomia.

Segundo Martins et al. ${ }^{18}$ (1998), além da exposição cirúrgica seguida da irrupção natural indicada em casos de inclinação axial favorável, existe outra alternativa de tratamento, em casos de dentes retidos após a exposição cirúrgica, que consiste na aplicação de forças ortodônticas. No presente caso, não houve necessidade de tratamento ortodôntico, pois com sete dias da exposição cirúrgica, o dente já se apresentava com erupção satisfatória.

Em relação à má oclusão de Classe II, divisão 1, essa atinge a maior parte da população que procura tratamento ortodôntico, e, segundo Silva Filho et al. $^{19}$ e Freitas e Cavassan ${ }^{19}$, apresenta-se em $40 \%$ dos casos, com uma etiologia multifatorial e muitas vezes está associada a outros problemas, como a atresia da maxila e a mordida aberta. No estudo em questão, apresentou-se também associada ao atraso de erupção do dente 22.

A má oclusão Classe II, divisão 1, caracterizada por uma desarmonia dentária no sentido ântero-posterior, torna-se mais grave quando associada a uma desarmonia esquelética, que pode ser decorrente de uma deficiência mandibular, de uma protrusão maxilar ou de uma combinação de ambas. Essas alterações levam ao comprometimento do perfil facial, muitas vezes com consequências psicossociais ${ }^{20}$.

\section{Considerações finais}

A técnica da ulotomia, como um passo inicial para o tratamento da má-oclusão, é um procedimento simples, de baixo custo e eficaz quando bem planejada. Por isso, é importante orientar os pais e responsáveis sobre possíveis atrasos na erupção dentária, evitando danos futuros no desenvolvimento dentário. $\mathrm{O}$ cuidadoso planejamento, associado a um adequado acompanhamento, permite que $o$ paciente alcance uma dentição com características estético funcionais satisfatórias. 


\section{Abstract}

Objective: To report a case in which surgical technique ulotomia was used as initial treatment for correction of dental malocclusion avoiding major changes in occlusion. Case report: Patient seven-year-old female, came to referring dental care have a delayed eruption of tooth 12. Gingival tissue paler color was observed and, at the touch, showed to said incisal edge of the tooth. Moreover, we verified the presence of gingival inflammation and hyperplasia in the region of the maxillary anterior teeth, due to occlusion problems that prevented normal closure of the mouth, leading to dental patient's condition breather. Thus, we chose to ulotomia because it is a minimally invasive surgical procedure, aiming only excision of gum tissue that covered the crown of unerupted tooth, thus allowing an unobstructed path to come to occupy its position in the dental arch. Final considerations: the ulotomia a procedure is easy to perform for the professional and speedy recovery for the child patient, with an initial step in the treatment of poor-olcusão.

Keywords: Tooth eruption. Corrective orthodontics. Malocclusion.

\section{Referências}

1. Assed S, Queiroz AM. Erupção dental. In: Assed S. Odontopediatria: bases científicas para a prática clínica. 1. ed. São Paulo: Artes Médicas; 2005. p. 173-212.

2. Boj JR, Garcia-Godoy F. Multiple eruption cysts: report of case. J Dent Child 2000; 67(4):282-4.

3. Oliveira INM, Stuani MBS, Stuani AS, Mizusaki CI. Fatores etiológicos locais que interferem na erupção dos dentes permanentes. Stoma 2002; 63:18-33.

4. Guedes-Pinto AC. Odontopediatria. 1. ed. São Paulo:Ed. Santos; 2003.

5. Silva FW, Queiroz AM, Stuani AS, Nelson-Filho P, Diaz-Serrano K. Ojal quirúrgico (ulotomia) ¿cuando y como realizarlo?: Reporte de 3 casos clínicos. Acta Odontol Venez 2008; 46(3):326-8.

6. Carreira MA, Pacenko MR, Matsumoto MA, Dekon AFC. Cisto de erupção e resolução cirúrgica por ulotomia: caso clínico. J Appl Oral Sci 2003; 11(3):234.

7. Gregori C, Motta LFG. Cirurgia em odontologia. In: Guedes Pinto, AC. Odontopediatria. 7. ed. São Paulo: Santos; 2003. p. $531-52$.

8. Issao M, Guedes- Pinto AC. Manual de Odontopediatria. 10. ed. São Paulo: Pancast; 1999.

9. Bayram M, Özer M,Sener I. Bilaterallly impacted maxillary central incisors: surgical exposure and orthodontic treatment: a case report. J Contemp Dent Pract 2006;7(4):98-105.

10. Guedes-Pinto AC. Odontopediatria Clínica. Série EAP APCD. São Paulo: 6 ${ }^{a}$ ed. Artes Médicas; 1998.

11. Strang RHA. A textbook of Orthodontics. Philadelphia: Lea \& Febiger; 1950

12. Cavalcante AL, Paiva LCA. Utilização da ulotomia na clínica infantil: relato de caso. Publ UEPG Ci Biol Saúde 2006; 12(3):39-42.
13. Stuani AS, Souza AHF, Stuani AS, Stuani MBS. Solução alternativa para incisivo superior impactado. Rev Ibero-am Odontopediatr Odontol Bebê 2004; 7(38):335-40.

14. Koch G, Modeér T, Pousen S, Rasmussen P. Odontopediatria: Uma abordagem clínica. 2. ed. São Paulo: Santos; 1995.

15. Katchburian E, Arana-Chavez VE. Histologia e embiologia oral. 1. Ed. São Paulo: Medicina Panamericana; 1999.

16. Martinez JA, Mota LFG, Miranda IMAD, Guedes- Pinto AC. Cirurgia em odontopediatria. In: Guedes-Pinto AC. Odontopediatria clínica. São Paulo: Artes Médicas; 1998. p.167-90.

17. Puricelli E, Ponzoni D. Cirurgia bucal pediátrica. In: TOLEDO AO. Odontopediatria: Fundamentos para a prática clínica. 3. ed. São Paulo: Premier; 2005. p. 315-30.

18. Martins DR, Kawakami RY, Henriques JFC, Janson GRP. Impacção dentária: condutas clínicas e apresentação de casos clínicos. Rev Dent Press Ortodon Ortop Facial 1998; $3(1): 12-22$.

19. Silva Filho OG, Freitas SE, Cavassan A,O. Prevalência de oclusão normal e má oclusão em escolares da cidade de Bauru (São Paulo). Parte II: influência da estratificação sócio-econômica. Rev Odontol Univ São Paulo 1990; 4(3):189-96.

20. Freitas JC. Má oclusão Classe II, divisão 1, de Angle com discrepância ântero-posterior acentuada. Rev Dental Press Ortodon Ortop Facial Maringá 2009; 14(2):131-43.

\section{Endereço para correspondência:}

Rachel Reinaldo Arnaud

Av. Pombal, no 1413 , Manaíra.

58038-240 João Pessoa- PB Brasil

Fone: (83) 3226-2651

E-mail: rrarnaud@hotmail.com

Recebido: 30/01/2014. Aceito: 21/07/2014. 